\title{
Cormorbidity index could help select elderly patients for SES implantation
}

A multivariate analysis of data from the international e-SELECT registry indicates that percutaneous coronary intervention with sirolimus-eluting stent (SES) implantation could be an appropriate treatment strategy for selected patients aged $>80$ years. This finding is important because elderly individuals are under represented in clinical trials and, therefore, outcome data in this group are lacking.

e-SELECT is a multicenter, surveillance registry of patients who undergo implantation of Cypher ${ }^{\circledR}$ Select or Cypher ${ }^{\circledR}$ Select Plus (Cordis Corporation, Miami Lakes, FL, USA) SESs. Among the 15,147 patients prospectively registered between 2006 and 2008, 675 were aged $>80$ years. As might be expected, some differences in baseline characteristics were observed between the octogenarians and younger patients. Most notably, the prevalence of comorbidities, as classified by the Charlson comorbidity index, was higher in the older group.
Rates of stent thrombosis, cardiac death, and major bleeding were fairly low in both groups 1 year after intervention, but were significantly higher among patients aged $>80$ years. Rates of targetvessel revascularization at 1 year were not significantly different between the two age groups. All stent thrombosis in the older group occurred within 6 months of the procedure, despite only $73 \%$ of these patients being treated with dual antiplatelet therapy at 1 year. The Charlson comorbidity index was the most powerful independent predictor of adverse events among octogenarians. The authors conclude that using this index "could further improve the screening of elderly patients for coronary revascularization."

\section{Alexandra King}

Original article Hong, Y. J. et al. Sirolimus-eluting coronary stents in octogenarians: a 1-year analysis of the worldwide e-SELECT registry. JACC Cardiovasc. Interv. 4, 982-991 (2011) 